\title{
Modulation of Beta Oscillations in the Subthalamic Nucleus with Prosaccades and Antisaccades in Parkinson's Disease
}

\author{
Akihiro Yugeta, ${ }^{1}$ William D. Hutchison, ${ }^{2,3}$ Clement Hamani, ${ }^{2}$ Utpal Saha, ${ }^{1}$ Andres M. Lozano, ${ }^{2}$ Mojgan Hodaie, ${ }^{2}$ \\ Elena Moro, ${ }^{1}$ and Robert Chen ${ }^{1}$ \\ ${ }^{1}$ Division of Neurology, Toronto Western Research Institute, and the Edmond J. Safra Program in Parkinson's Disease, ${ }^{2}$ Division of Neurosurgery, and \\ Toronto Western Research Institute, and ${ }^{3}$ Department of Physiology, University of Toronto, Toronto, Ontario M5T 2S8, Canada
}

Increased oscillations in the beta band are thought to be related to motor symptoms of Parkinson's disease (PD). Previous studies have shown that beta-band desynchronization in the subthalamic nucleus (STN) is reduced just before and during limb movements. While the STN is part of the basal ganglia (BG)-thalamocortical circuit controlling limb movements, it is also part of the BG-brainstem projection controlling saccadic eye movements. Late-stage PD patients have deficits in saccades in addition to difficulties with limb movements arising from impaired functions of the BG. We investigated saccade-related changes in beta-band (15-30 Hz) oscillatory activities in the human STN while PD patients performed visually guided prosaccades and antisaccades, the latter requiring suppression of reflexive responses and volitional initiation of saccades. We recorded local field potentials from deep brain stimulation electrodes implanted in the STN in human PD patients 1-5 d after surgery and compared prosaccades and antisaccades with these and with limb movements. Saccade-related beta-band desynchronizations were observed just before and during saccades in all subjects, suggesting that reduction of beta-band oscillatory activity in the STN is related to preparation and execution of saccades. Furthermore, beta-band desynchronizations for antisaccades started earlier, were sustained for longer periods, were of greater magnitude, and were observed more often than prosaccades. Beta-band desynchronization in the STN may reflect the additional processes associated with suppression of reflexive responses and volitional execution of saccades in the opposite direction.

\section{Introduction}

In Parkinson's disease (PD), midbrain dopaminergic cell loss leads to dysfunction of the basal ganglia (BG). The BG are thought to be involved in response selection by determining whether a given movement is suppressed or allowed by exerting or removing tonic inhibition of the thalamocortical motor loops controlling limb movements. The BG also tonically inhibit the brainstem motor centers controlling innate movements, including saccades (Hikosaka et al., 2000). Previous studies have documented that PD patients have delayed saccade latencies and hypometric primary saccades, often showing a series of small step-like saccades (White et al., 1983; Briand et al., 1999; Chan et al., 2005). Furthermore, antisaccades are more impaired than those of visually guided saccades in PD patients. Subthalamic

Received May 28, 2012; revised Feb. 28, 2013; accepted March 2, 2013.

Author contributions: A.Y., W.D.H., and R.C. designed research; A.Y., W.D.H., C.H., U.S., A.M.L., M.H., E.M., and R.C. performed research; A.Y. and W.D.H. contributed unpublished reagents/analytic tools; A.Y. and W.D.H. analyzed data; A.Y., W.D.H., and R.C. wrote the paper.

A.Y. is supported by the Canadian Institutes of Health Research (CIHR) and Dystonia Medical Research Foundation (DMRF) Canada. W.D.H. is supported by CIHR, DMRF, and Medtronic A.M.L. is supported by the Canada Research Chair in Neurosciences. R.C. is supported by a (IHR Industry-Partnered (Medtronic) Investigator Award and the Catherine Manson Chair in Movement Disorders. We thank Dr. Neil Mahant for helpful comments.

The authors declare no competing financial interests.

Correspondence should be addressed to Akihiro Yugeta, Department of Neurology, The University of Tokyo Hospital, 7-3-1 Hongo, Bukyo-ku, Tokyo, 113-8655, Japan. E-mail: yugetaa-tky@umin.ac.jp.

E. Moro's present address is Movement Disorder Unit, Department of Psychiatry and Neurology, Centre Hospitalier Universitaire de Grenoble, 38043 Grenoble, France.

DOI:10.1523/JNEUROSCI.2564-12.2013

Copyright $\odot 2013$ the authors $\quad 0270-6474 / 13 / 336895-10 \$ 15.00 / 0$ nucleus (STN) deep brain stimulation (DBS) improves not only somatomotor symptoms but also saccade initiation and inhibition in PD (Rivaud-Péchoux et al., 2000; Fawcett et al., 2010; Yugeta et al., 2010).

Beta-band oscillatory activities in sensorimotor cortices and in the BG have been observed both in nonhuman primates and in humans (Murthy and Fetz, 1992; Sanes and Donoghue, 1993; Baker et al., 1997; Donoghue et al., 1998; Levy et al., 2000; Cassidy et al., 2002; Williams et al., 2005). The betaband event-related desynchronization $(\beta$-ERD) is considered to be involved in preparation and execution of limb movements (Kühn et al., 2004). Although the oscillatory activity change related to eye movements has been observed in human BG (Fawcett et al., 2007), it is still unclear how the synchronization or desynchronization in each frequency band plays a role in controlling saccadic eye movements. The aim of the present study was to investigate saccade-related modulation of oscillatory activities in the human STN. We used a prosaccade task, in which subjects made saccade toward visual cues, and an antisaccade task, in which subjects volitionally made saccades away from visual cues. We recorded local field potentials (LFPs) from DBS electrodes in the STN in PD patients during these saccade tasks. We hypothesized that, similar to $\beta$-ERDs for hand movements, the saccade-related beta-band (15-30 $\mathrm{Hz}$ ) desynchronizations ( $\beta$-SRDs) would be observed just before and during saccades. We further hypothesized that $\beta$-SRDs for antisaccades would be larger than those for prosaccades, because antisaccades require the inhibition of reflex- 
Table 1. Characteristics of subjects

\begin{tabular}{|c|c|c|c|c|c|c|c|c|}
\hline Patient & Age & Sex & $\begin{array}{l}\text { Duration of } \\
\text { disease (y) }\end{array}$ & DBS & $\begin{array}{l}\text { Medication } \\
\text { during } \\
\text { recording }\end{array}$ & $\begin{array}{l}\text { Hoen } \\
\text { Yahr } \\
\text { stage }\end{array}$ & $\begin{array}{l}\text { UPDRS-III } \\
\text { (off-medication) }\end{array}$ & $\begin{array}{l}\text { LED } \\
(\mathrm{mg} / \mathrm{d})\end{array}$ \\
\hline 1 & 61 & $\mathrm{~F}$ & 17 & $\mathrm{R} / \mathrm{L}$ & On & 3 & 65 & 790 \\
\hline 2 & 53 & $M$ & 6 & $\mathrm{R} / \mathrm{L}$ & On & 2 & 20.5 & 2327.5 \\
\hline 3 & 53 & $M$ & 6 & $\mathrm{R} / \mathrm{L}$ & On & 3 & 45.5 & 600 \\
\hline 4 & 63 & $M$ & 22 & $\mathrm{R} / \mathrm{L}$ & On & 3 & 46.5 & 1065 \\
\hline 5 & 55 & $M$ & 8 & $\mathrm{R} / \mathrm{L}$ & On & 2 & 30.5 & 900 \\
\hline 6 & 61 & $M$ & 17 & $R / L$ & On & 3 & 42.5 & 1800 \\
\hline 7 & 58 & $M$ & 12 & $\mathrm{R} / \mathrm{L}$ & On & 2 & 51 & 1199 \\
\hline 8 & 64 & M & 8 & $\mathrm{R} / \mathrm{L}$ & Off & 3 & 20 & 213 \\
\hline 9 & 58 & $M$ & 24 & $\mathrm{R} / \mathrm{L}$ & Off & 2 & 33.5 & 1875 \\
\hline 10 & 56 & $M$ & 10 & $\mathrm{R} / \mathrm{L}$ & Off & 2 & 26 & 1075 \\
\hline 11 & 56 & $\mathrm{~F}$ & 13 & $\mathrm{R} / \mathrm{L}$ & Off & 3 & 31 & 1330 \\
\hline 12 & 52 & $M$ & 13 & $\mathrm{R} / \mathrm{L}$ & Off & 2 & 23.5 & 800 \\
\hline 13 & 49 & M & 8 & $\mathrm{R} / \mathrm{L}$ & Off & 2 & 23 & 1300 \\
\hline 14 & 48 & $\mathrm{~F}$ & 19 & $\mathrm{R} / \mathrm{L}$ & On & 3 & 56 & 1875 \\
\hline 15 & 60 & M & 13 & $\mathrm{R} /-$ & On & 3 & 70 & 3792 \\
\hline 16 & 71 & $\mathrm{~F}$ & 20 & $\mathrm{R} /-$ & On & 3 & 33 & 625.75 \\
\hline 17 & 75 & $\mathrm{~F}$ & 15 & $\mathrm{R} /-$ & Off & 3 & 44.5 & 3192 \\
\hline 18 & 61 & $\mathrm{~F}$ & 10 & $\mathrm{R} /-$ & On & 3 & 32 & 1750 \\
\hline 19 & 71 & M & 20 & $-/ \mathrm{L}$ & On & 3 & 65 & 920 \\
\hline 20 & 64 & $\mathrm{~F}$ & 9 & $-/ \mathrm{L}$ & Off & 3 & 43 & 1700 \\
\hline Average & 59.4 & - & 13.5 & - & - & 2.65 & 40.10 & 1456.5 \\
\hline
\end{tabular}

LED indicates levodopa equivalent dose; $R$ and L, right and left STN.

ive responses and greater driving signals for intended saccades than prosaccades.

Because the ventral STN receives neural inputs from the frontal eye field and the supplementary eye field (Monakow et al., 1978; Huerta et al., 1986; Huerta and Kaas, 1990), whereas signals for limb movements project from the primary and supplementary motor cortices to the dorsal STN (Monakow et al., 1978; Nambu et al., 1996), we compared $\beta$-SRDs with $\beta$-ERDs for self-paced wrist movements with a prediction that $\beta$-SRDs might be localized to the ventral STN, whereas $\beta$-ERDs for wrist movement would be found in the dorsal STN.

\section{Materials and Methods}

Subjects. The clinical characteristics of the patients are listed in Table 1. Twenty PD patients were studied, 12 in the on-medication state and 8 in the off-medication state ( $\sim 12 \mathrm{~h}$ off medications). There were 7 women and 13 men, aged $59.5 \pm 7.2$ years (mean \pm SD; range, 48-75) with disease duration of $13.5 \pm 5.5$ (range, $6-24$ ) years. Their levodopa equivalent dose was $1456.5 \pm 879.2 \mathrm{mg}$ (range, 213-3792; for calculation, see Tomlinson et al., 2010). All of the patients self-reported being right handed. The study was approved by the University Health Network Research Ethics Board. Written informed consents were obtained from all participants.

Experimental procedure. One to $5 \mathrm{~d}$ after surgery, when DBS leads were externalized and before implantation of the implantable pulse generator, LFPs were recorded from DBS electrodes (model 3387; Medtronic) implanted in STN. The DBS electrodes have four platinum/iridium cylindrical contacts numbered $0-3$, with contact 3 being the most dorsal and 0 the most ventral (Fig. 1). We calculated wavelet power in bipolar derivations-left contact 3 (L3)-L2 and right contact 3 (R3)-R2 as dorsal contact pairs, L2-L1 and R2-R1 as middle contact pairs, and L1-L0 and R1-R0 as ventral contact pairs-to minimize far-field potentials. Electrodes were $1.27 \mathrm{~mm}$ in diameter, $1.5 \mathrm{~mm}$ in length, and separated from the next closest contact by $1.5 \mathrm{~mm}$. The patients performed a prosaccade task and an antisaccade task in which they were instructed to look in the opposite direction to the visual cue ("look away", see details below).

Experimental setup. LFPs were recorded from the DBS electrodes implanted in the STN using linked earlobes as references. Electrooculography (EOG) was recorded with two $\mathrm{Ag}-\mathrm{AgCl}$ electrodes placed on the

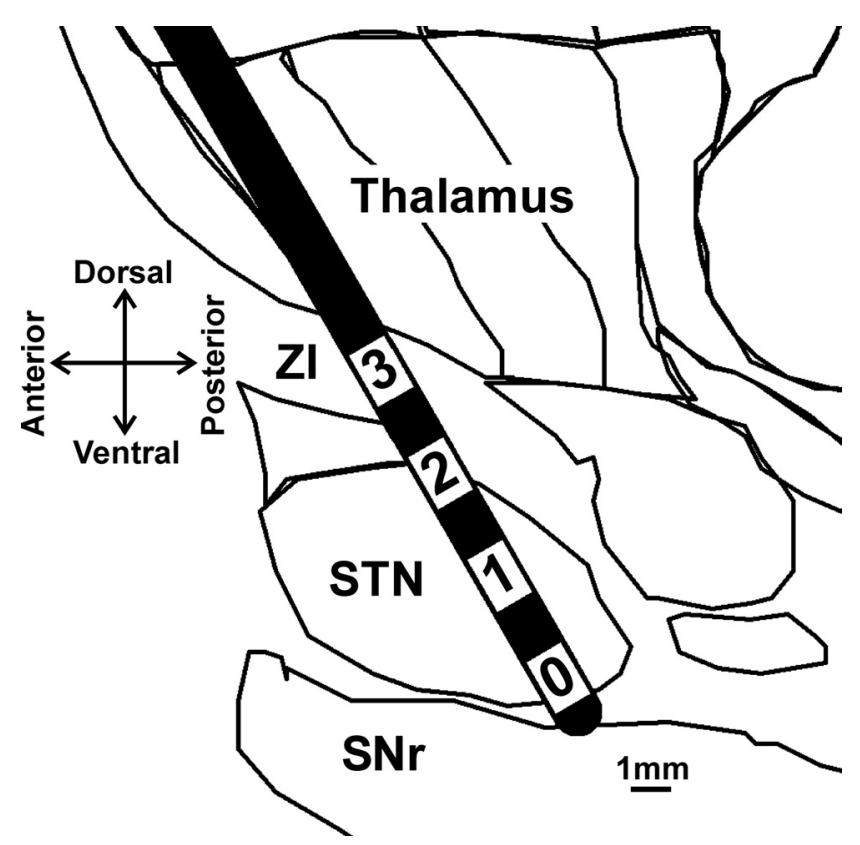

Figure 1. Sagittal section of the STN. Black bar represents the DBS electrode. Numbers from 0 to 3 represent positions of each contact. The scale is adjusted according to the average distance between the anterior and the posterior commissure $(26.3 \mathrm{~mm})$ for the subjects in this study. SNr indicates substantia nigra pars reticulata.

bilateral outer canthi for horizontal eye movement. The high-pass filter was set at $0.05 \mathrm{~Hz}$ and the low-pass filter at $500 \mathrm{~Hz}$. The sampling rate was $2500 \mathrm{~Hz}$. In addition, surface electromyography (EMG) was recorded from the extensor carpi radialis (ECR) muscle while the subjects performed self-paced wrist extension movements. Synamps and Neuroscan 4 software (Compumedics USA) was used for recording of LFPs, EOGs, and EMGs.

Saccade tasks and wrist extension task. Visual fixation and target points were indicated by red light-emitting diodes (LEDs) with diameter of 4.5 $\mathrm{mm}$ (visual angle $\sim 0.3$ degree) mounted on a blackboard. The subject's eyes were positioned $93 \mathrm{~cm}$ away from the board, which placed the left and right LEDs at $\sim 20$ degrees from the central LED. A custom script in Spike2 version 7 (Cambridge Electronic Design) was used to control the LEDs. In the prosaccade task, the subjects initially fixed on the LED at the center of the board. After $1500 \mathrm{~ms}$, the central fixation point was turned off and the target point (cue) was simultaneously turned on at 20 degrees to the left or right randomly. The subjects were instructed to make a saccade to the new position as quickly as possible. In the antisaccade task, the fixation point and the cue were turned on and off in the same way as in the prosaccade task, but the subject had to make a saccade toward the location opposite to the cue. In other words, the actual target point for the saccade was a point opposite to where the cue stimulus appeared. Each task comprised a total of 50 trials to the right or left side that were randomly presented with $50 \%$ probability. The saccade tasks were presented in a pseudorandom order in each subject and were counterbalanced across subjects.

For the wrist movement task, patients with bilateral or left STN DBS extended their right wrist and patients with right STN DBS extended their left wrist at their own pace every 5-10 $\mathrm{s}$ without any visual or auditory cues $\sim 50$ times.

Confirmation of electrode contact locations. The methods to assess the location of DBS electrode contacts within the STN have been described in detail previously (Hamani et al., 2008; Kuriakose et al., 2010). Briefly, preoperative $\mathrm{T} 2$ and postoperative axial 3D inversion recovery images were fused. The anterior and posterior commissures were registered and the location of each electrode contact (center of the sphere-shaped MRI artifact) was established relative to the midcommissural point and the STN.

Data analysis and statistics. Onset of saccades was detected using EOG. Saccades with latencies of $<60 \mathrm{~ms}$ were considered anticipatory 
A Saccade trace and raw LFPs during leftward prosaccade

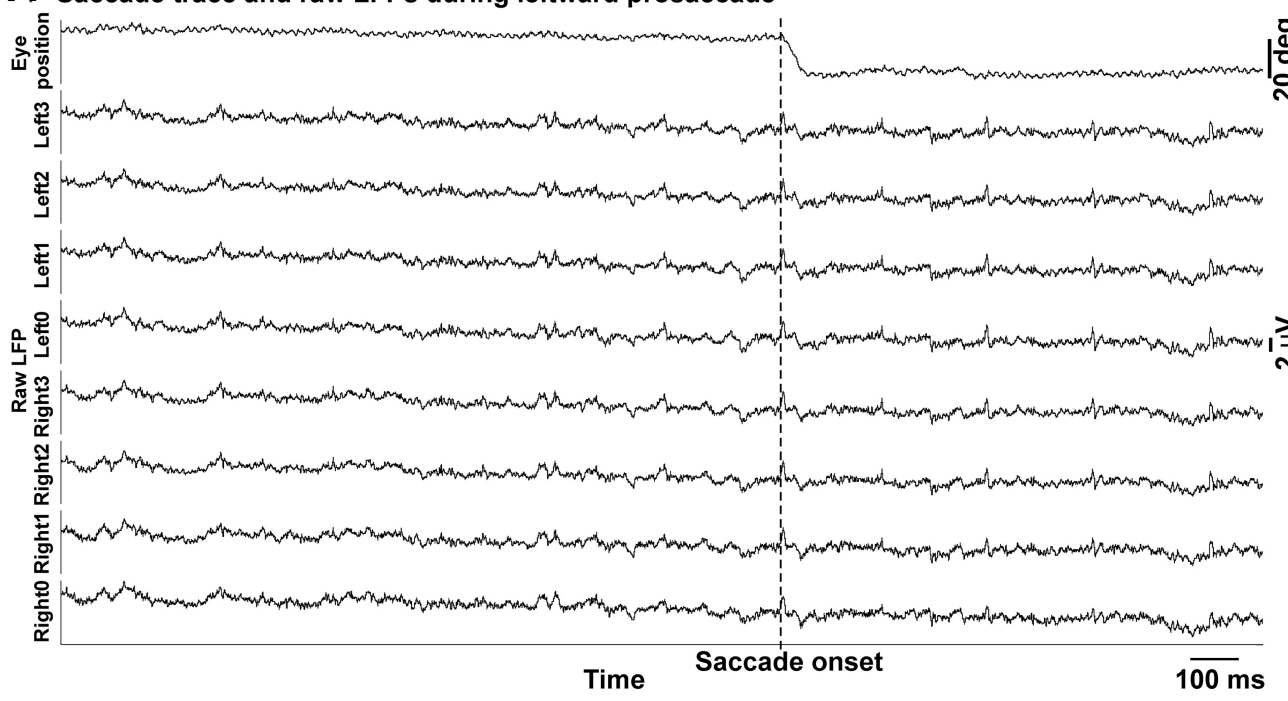

\section{B Saccade trace and raw LFPs during rightward antisaccade}

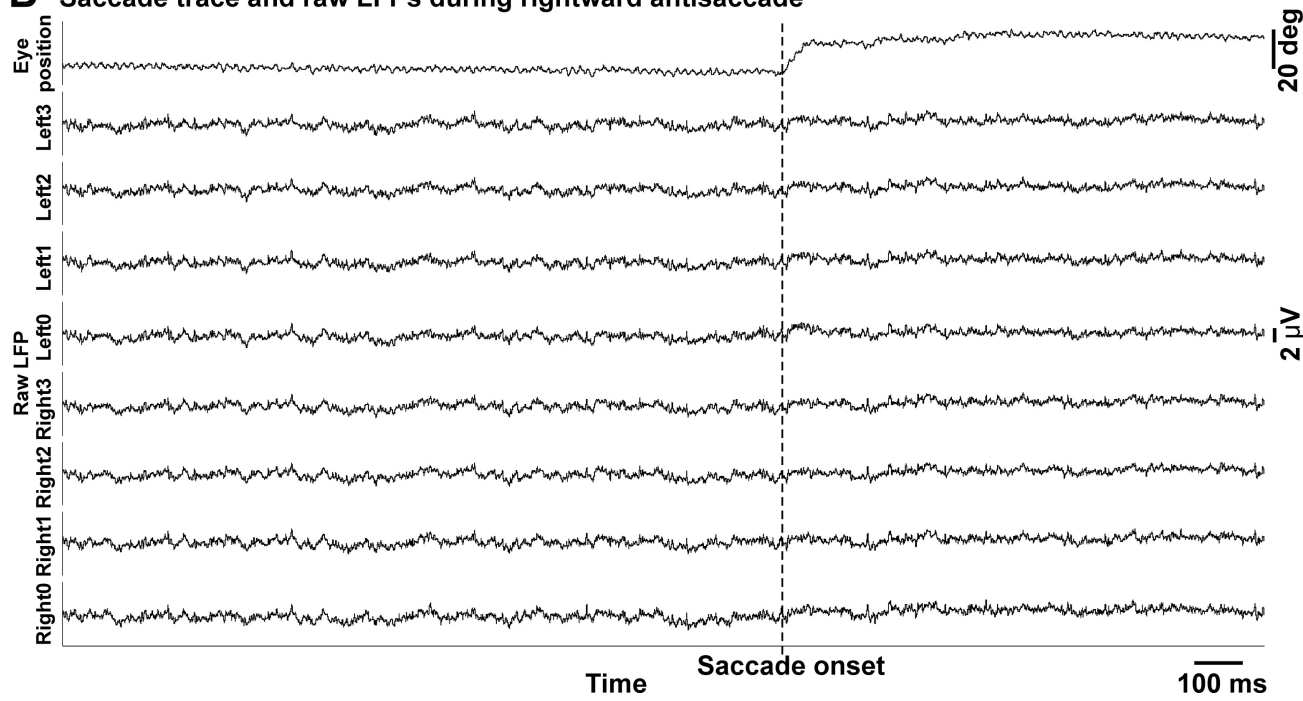

C Baseline power spectrum during leftward prosaccade

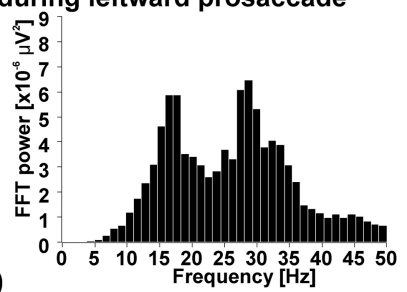

主

Peri-saccade power spectrum during leftward prosaccade

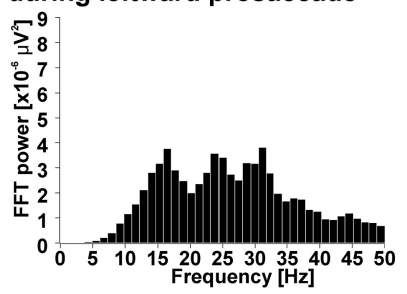

E

Baseline power spectrum during rightward antisaccade

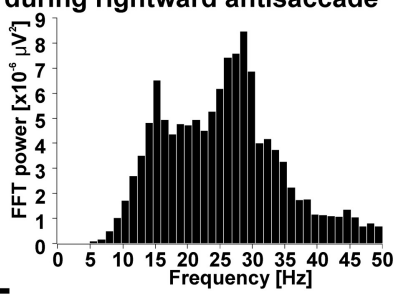

$F$

Peri-saccade power spectrum during rightward antisaccade

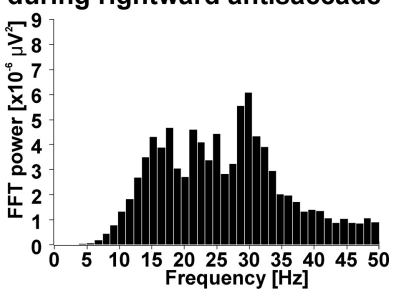

Figure 2. Raw LFPs and beta-band power spectra in case 6.A, Saccade trace and LFPs for prosaccades. B, Saccade trace and LFPs for antisaccades. The first row shows eye positions recorded from EOG; the other 6 rows show LFPs recorded from DBS electrodes. The beta-band power spectrum in contact R2-R1 for the baseline period (from 1500 to 500 ms before saccade onset) for prosaccades is shown in Cand that for antisaccades is shown in $\boldsymbol{E}$. The beta-band power spectrum in perisaccade period (from $100 \mathrm{~ms}$ before saccade onset to $900 \mathrm{~ms}$ after saccade onset) for prosaccades is shown in $\boldsymbol{D}$ and that for antisaccades is shown in $\boldsymbol{F}$. Beta power shows two peaks in the baseline period. Reduction in beta power during prosaccades and antisaccades appeared to be slightly greater in the high-beta $(20-30 \mathrm{~Hz})$ than in the low-beta $(15-19 \mathrm{~Hz})$ band.

(Kalesnykas and Hallett, 1987; Braun and Breitmeyer, 1988; Fischer and Weber, 1992; Weber et al., 1993; Reuter-Lorenz et al., 1995; Delinte et al., 2002). Error trials include trials with directional errors, anticipation saccades, delayed onset of saccade after $1000 \mathrm{~ms}$ from cue onset, and those without saccades and all were excluded from the analysis. Although we analyzed the presence of desynchronization in the $5-100 \mathrm{~Hz}$ range using joint time frequency wavelet spectrograms, we focused on changes in the beta-band $(15-30 \mathrm{~Hz})$. Power change was calculated in bipolar derivations across DBS contacts by Morlet wavelets, with wavelet parameter set at 4 , averaged on saccade onset. The continuous Molet wavelet transformation contains both the time domain and the frequency domain information, while the fast Fourier transformation (FFT) contains only the frequency domain information. The continuous wavelet transformation is therefore advantageous over the FFT because the time course of frequency information can be observed. To detect the presence and the timing of significant $\beta$-SRDs and $\beta$-ERDs, the wavelet power from 500 $\mathrm{ms}$ before to $500 \mathrm{~ms}$ after saccade onset was compared with the power in the baseline, defined as 1500 to $1000 \mathrm{~ms}$ before saccade onset (Fig. 3, black bars on the abscissa) using the $\mathrm{Z}$ test with the threshold set at
1.51. Morlet wavelets and $\mathrm{Z}$ tests were calculated by a custom script in MATLAB version 7.10 (MathWorks). The onset times of $\beta$-SRDs and $\beta$-ERDs were the times that the wavelet power fell below the threshold and offset times were the time the wavelet power returned to above the threshold. The time from the onset to the offset was considered the durations of $\beta$-SRDs and $\beta$-ERDs. Areas of significant $\beta$-SRDs and $\beta$-ERDs are identified by black lines in Figure 3. The largest reduction in the amplitude of the wavelet power is considered the amplitude of $\beta$-SRDs and $\beta$-ERDs. The incidences of significant $\beta$-SRDs for the DBS contact pairs studied were compared between the right and left STN, between the STN ipsilateral and contralateral to the saccade direction, and between prosaccades and antisaccades using the Fisher's exact test (FET). Onset of wrist movements was detected using EMG of the ECR muscle. The wavelet power of LFPs during self-paced wrist movements was calculated by averaging over the onset of wrist extension. Onset, duration, and amplitude of $\beta$-SRDs and $\beta$-ERDs were compared between tasks (prosaccades, antisaccades, and wrist extension) and between contact positions (dorsal, middle, and ventral contact pairs) using two-way ANOVA. In addition, post hoc Tukey-Kramer multiple-comparison tests were applied when 
ANOVA showed significance. The difference in distances from the STN to the contact pairs showing $\beta$-SRDs and $\beta$-ERDs were evaluated by Kruskal-Wallis rank-sum test. If both contacts were inside the STN, then a value of 0 was assigned to the distance; if one contact was inside the STN and another was at the border of the upper or the lower edge of the STN, a value of 0.5 or -0.5 was assigned to the distance. If the contact pairs were 1 or 2 contacts away from the border, then a value of 1.5 or 2.5 was assigned to the distance. Correlations were calculated between $\beta$-SRDs or $\beta$-ERDs for wrist movements and clinical variables such as age at surgery, onset age of disease, disease duration, Unified Parkinson's Disease Rating Scale part III (UPDRS-III) motor scores, and Hoehn and Yahr stages. Onsets, durations, and amplitudes of $\beta$-SRDs for prosaccades or for antisaccades were compared between the right and the left STN, between the ipsilateral and contralateral STN, and between on-medication and offmedication states using two-way ANOVA. We considered $p \leq 0.05$ as significant and $0.05<$ $p \leq 0.10$ as a nonsignificant trend.

\section{Results}

The onset latencies of prosaccades were $323.6 \pm 47.2 \mathrm{~ms}$, whereas those of antisaccades were $426.9 \pm 77.4 \mathrm{~ms}$ from the onset of the visual cue (averaged visual cue onsets are indicated by the dash-dot lines in Fig. $4 A, B)$. The percentage of errors trials were $22 \pm 14 \%$ (mean $\pm \mathrm{SD}$ ) for prosaccades and $42 \pm 23 \%$ for antisaccades.

Raw LFPs and baseline and perisaccade FFT power spectra during prosaccades and antisaccade are shown in Figure 2. Typical wavelet spectrograms during prosaccades and antisaccades are shown in Figure 3 (case 6). Reductions of betaband $(15-30 \mathrm{~Hz})$ power in the STN were observed just before and during saccades in both the dorsal contact pairs on the right side and the middle contact pairs on both the right and the left sides for both prosaccades and antisaccades (Fig. 3). This saccade-related reduction in betaband power in the STN was observed in all subjects in either the contralateral or the ipsilateral STN or bilaterally (Table 2). $\beta$-SRDs were observed with similar frequencies in both the right (15 of 18 , or $83.3 \%$ ) and the left STN (12 of 16, or $75.0 \% ; p=0.68, \mathrm{FET})$. We found $\beta$-SRDs in 25 of $34(73.5 \%)$ STN ipsilateral to the saccade direction and in 25 of $34(73.5 \%)$

STN contralateral to the saccade direction, indicating that saccades are associated with bilateral $\beta$-SRDs. In addition, $\beta$-SRDs occurred more often during antisaccades (in 27 of $34,79.4 \%$ of STN) than prosaccades (in 18 of $34,52.9 \%$ of STN; $p=0.039$, FET). $\beta$-SRDs were observed in 13 of $34(38.2 \%)$ ipsilateral STN and in 11 of $34(32.4 \%)$ contralateral STN during prosaccades and in 22 of $34(64.7 \%)$ ipsilateral STN and in 21 of $34(61.8 \%)$ of contralateral STN during antisaccades. Therefore, the frequen-
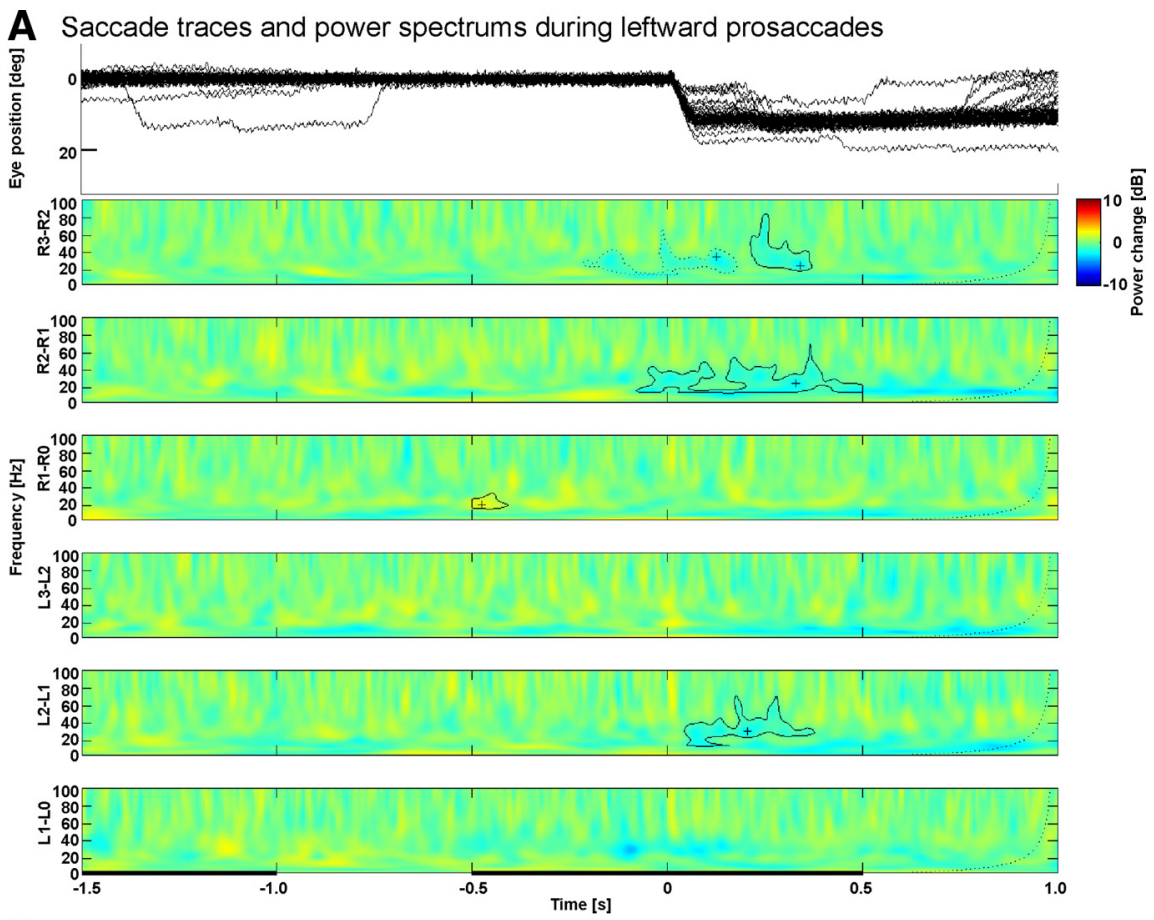

B Saccade traces and power spectrums during rightward antisaccades
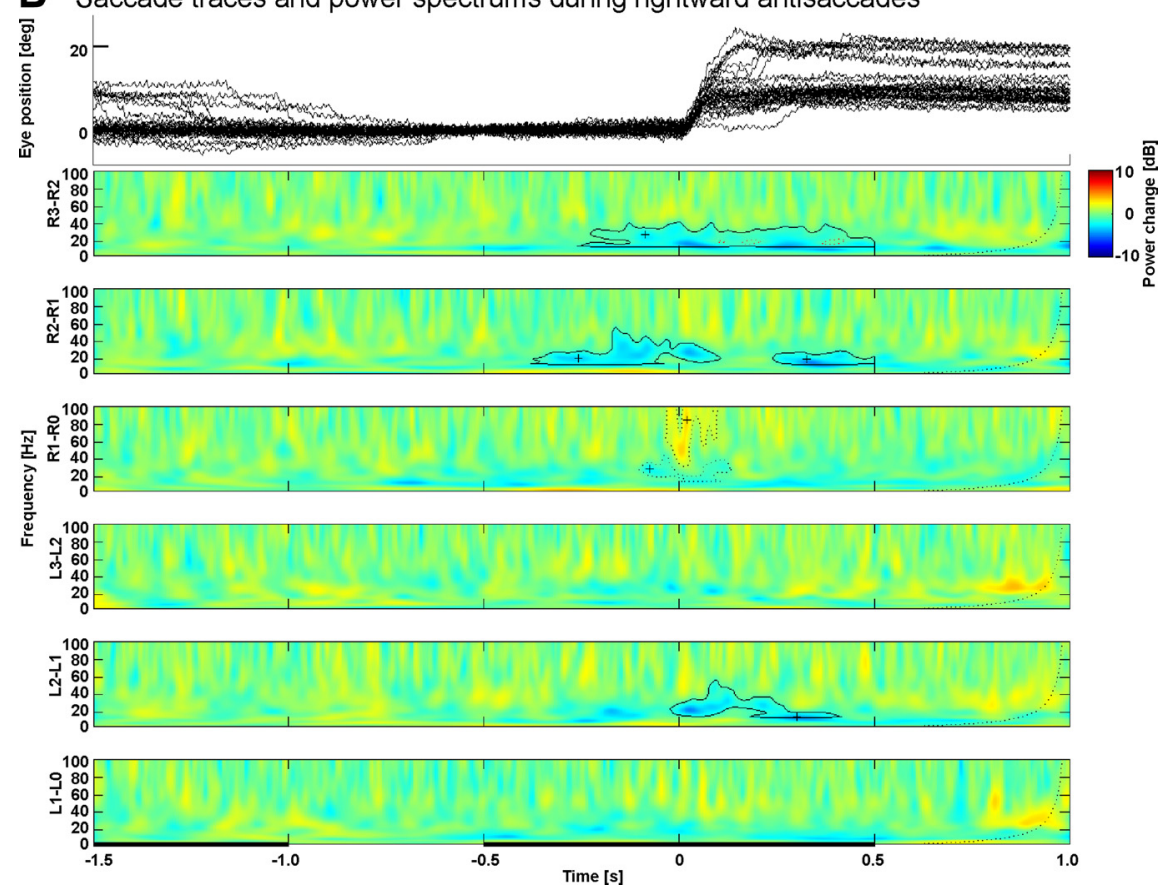

Figure 3. Saccade-related changes in the wavelet spectrograms of LFPs in case $6 . A$, Averaged wavelet spectrograms obtained from 40 leftward prosaccades. $\boldsymbol{B}$, Averaged wavelet spectrograms obtained from 36 rightward antisaccades. Time 0 represents saccade onset. The first rows of each panel show traces of saccades recorded from EOG; the other 6 rows show wavelet spectrograms of LFPs recorded from DBS electrodes. Red represents synchronization of LFPs, blue represents desynchronization. Desynchronizations appeared to be more prominent in the high-beta $(20-30 \mathrm{~Hz})$ than in the low-beta $(15-19 \mathrm{~Hz})$ band.

cies of $\beta$-SRDs were similar in the ipsilateral and contralateral STN nuclei during both prosaccades and antisaccades, although $\beta$-SRDs occurred more often for antisaccades than for prosaccades.

$\beta$-SRDs in the STN started a few hundred milliseconds before the saccade onset and were sustained during saccadic eye movement (Fig. 3, Fig. $4 A, B$ ). The onsets of $\beta$-SRDs and $\beta$-ERDs showed normal distributions ( $p>0.1$, Kolmogorov-Smirnov test) 
Table 2. $\beta$-SRD in each pair of DBS contacts

\begin{tabular}{|c|c|c|c|c|c|c|c|c|}
\hline \multirow[b]{2}{*}{ Case } & \multirow[b]{2}{*}{ Saccade direction } & \multirow[b]{2}{*}{ Task } & \multicolumn{6}{|c|}{ Pairs of DBS contacts } \\
\hline & & & R1-R0 & $\mathrm{R} 2-\mathrm{R} 1$ & R3-R2 & $\mathrm{L} 1-\mathrm{L} 0$ & L2-L1 & L3-L2 \\
\hline \multirow[t]{3}{*}{1} & \multirow[t]{2}{*}{ Rightward } & Pro & - & - & - & - & - & - \\
\hline & & Anti & + & - & - & - & - & - \\
\hline & Leftward & Anti & + & - & - & - & - & - \\
\hline \multirow[t]{2}{*}{2} & \multirow[t]{2}{*}{ Rightward } & Pro & - & - & - & - & - & - \\
\hline & & Anti & - & - & - & - & - & - \\
\hline \multirow[t]{4}{*}{3} & \multirow[t]{2}{*}{ Rightward } & Pro & - & + & + & - & + & - \\
\hline & & Anti & - & + & + & + & - & - \\
\hline & Leftward & Pro & + & - & + & + & - & - \\
\hline & & Anti & - & - & + & + & + & + \\
\hline 4 & Rightward & Pro & + & - & - & - & - & - \\
\hline & & Anti & - & - & - & - & - & - \\
\hline & & Anti & - & - & - & - & - & - \\
\hline 6 & Rightward & Pro & - & - & - & - & - & - \\
\hline & & Anti & - & + & - & - & + & - \\
\hline & Leftward & Pro & - & - & - & - & - & - \\
\hline & & Anti & + & + & - & + & - & - \\
\hline 7 & Rightward & Pro & - & + & - & - & - & - \\
\hline & & Anti & + & + & - & - & + & - \\
\hline & Leftward & Pro & + & + & - & - & + & - \\
\hline & & Anti & + & + & + & - & + & - \\
\hline 8 & Rightward & Pro & - & - & - & - & - & - \\
\hline & & Anti & + & - & + & - & - & - \\
\hline & Leftward & Pro & - & - & - & - & - & - \\
\hline & & Anti & - & - & - & - & - & + \\
\hline 11 & Rightward & Pro & - & + & - & - & - & - \\
\hline & & Anti & + & + & + & - & - & - \\
\hline & Leftward & Pro & + & - & - & - & - & - \\
\hline & & Anti & - & - & + & - & - & - \\
\hline 12 & Rightward & Pro & - & - & - & - & - & - \\
\hline & & Anti & + & + & + & + & + & + \\
\hline & Leftward & Pro & - & - & + & + & + & - \\
\hline & & Anti & + & + & + & + & + & + \\
\hline 13 & Rightward & Pro & - & + & - & - & + & - \\
\hline & & Anti & - & + & - & - & - & - \\
\hline & Leftward & Pro & - & - & - & - & + & - \\
\hline & & Anti & - & - & + & - & - & - \\
\hline 14 & Rightward & Pro & - & - & - & - & - & - \\
\hline & & Anti & - & + & - & - & + & - \\
\hline & Leftward & Pro & - & - & - & - & - & - \\
\hline & & Anti & + & - & - & - & - & - \\
\hline 15 & Rightward & Pro & + & - & + & {$[/]$} & {$[/]$} & {$[/]$} \\
\hline & & Anti & + & + & - & {$[/]$} & {$[/]$} & {$[/]$} \\
\hline & Leftward & Pro & + & + & - & {$[/]$} & {$[/]$} & {$[/]$} \\
\hline & & Anti & + & + & + & {$[/]$} & {$[/]$} & {$[/]$} \\
\hline 16 & Rightward & Pro & - & - & - & {$[/]$} & {$[/]$} & {$[/]$} \\
\hline & & Anti & - & - & - & {$[/]$} & {$[/]$} & {$[/]$} \\
\hline & Leftward & Pro & + & - & - & {$[/]$} & {$[/]$} & {$[/]$} \\
\hline & & Anti & + & - & - & {$[/]$} & {$[/]$} & $\begin{array}{c}{[/]} \\
\text { (Table continues) }\end{array}$ \\
\hline
\end{tabular}


Table 2. Continued

\begin{tabular}{|c|c|c|c|c|c|c|c|c|}
\hline \multirow[b]{2}{*}{ Case } & \multirow[b]{2}{*}{ Saccade direction } & \multirow[b]{2}{*}{ Task } & \multicolumn{6}{|c|}{ Pairs of DBS contacts } \\
\hline & & & R1-R0 & R2-R1 & $\mathrm{R} 3-\mathrm{R} 2$ & L1-L0 & L2-L1 & L3-L2 \\
\hline \multirow[t]{4}{*}{17} & \multirow[t]{2}{*}{ Rightward } & Pro & - & + & + & {$[/]$} & {$[/]$} & {$[/]$} \\
\hline & & Anti & - & + & - & {$[/]$} & {$[/]$} & {$[/]$} \\
\hline & \multirow[t]{2}{*}{ Leftward } & Pro & - & - & - & [/] & {$[/]$} & {$[/]$} \\
\hline & & Anti & - & + & - & {$[/]$} & {$[/]$} & {$[/]$} \\
\hline \multirow[t]{4}{*}{18} & \multirow[t]{2}{*}{ Rightward } & Pro & - & + & - & [/] & [/] & [/] \\
\hline & & Anti & - & - & - & [/] & [/] & [/] \\
\hline & \multirow[t]{2}{*}{ Leftward } & Pro & - & - & - & [/] & [/] & [/] \\
\hline & & Anti & - & + & - & {$[1]$} & {$[/]$} & {$[/]$} \\
\hline \multirow[t]{4}{*}{19} & \multirow[t]{2}{*}{ Rightward } & Pro & {$[/]$} & {$[/]$} & {$[/]$} & - & - & - \\
\hline & & Anti & {$[/]$} & {$[/]$} & {$[/]$} & + & - & + \\
\hline & \multirow[t]{2}{*}{ Leftward } & Pro & {$[/]$} & {$[/]$} & {$[/]$} & - & - & - \\
\hline & & Anti & {$[/]$} & {$[/]$} & {$[/]$} & - & + & + \\
\hline \multirow[t]{4}{*}{20} & \multirow[t]{2}{*}{ Rightward } & Pro & {$[/]$} & {$[/]$} & {$[/]$} & - & - & - \\
\hline & & Anti & {$[/]$} & {$[/]$} & {$[/]$} & + & + & + \\
\hline & \multirow[t]{2}{*}{ Leftward } & Pro & {$[/]$} & {$[/]$} & {$[/]$} & - & - & - \\
\hline & & Anti & {$[/]$} & {$[/]$} & {$[/]$} & - & + & + \\
\hline
\end{tabular}

Pro indicates prosaccades; anti, antisaccades; [/], no data because of unilateral cases.

and were different among the tasks: prosaccades, antisaccades, and self-paced wrist extensions ( $p<0.001$, two-way ANOVA; Fig. $5 A)$. Nonsignificant trends were observed both in the effect of the positions (dorsal, middle, and ventral) of contact pairs ( $p=$ 0.066, two-way ANOVA) and in the interaction between the tasks and the positions of contact pairs ( $p=0.055$, two-way ANOVA). The onsets of $\beta$-SRDs during antisaccades occurred earlier than those during prosaccades $(p=0.002$, Tukey-Kramer test). Moreover, the onsets of $\beta$-ERDs during self-paced wrist extensions were earlier than the onsets of $\beta$-SRDs during antisaccades $(p=0.003$, Tukey-Kramer test; Fig. $5 A$ ). During wrist extension, onsets of $\beta$-ERDs in the dorsal and the middle contact pairs were earlier than those in the ventral contact pairs $(p=0.005$ and $p=0.003$, Tukey-Kramer test), although onsets of $\beta$-SRDs during prosaccades and antisaccades were not significantly different among the positions of contact pairs.

The durations of $\beta$-SRDs and $\beta$-ERDs showed normal distributions ( $p>0.1$, Kolmogorov-Smirnov test) and were different among the tasks $(p<0.001$, two-way ANOVA). The duration of $\beta$-SRDs during antisaccades were longer than those during prosaccades $(p=0.007$, Tukey-Kramer test) and the duration of $\beta$-ERDs during self-paced wrist extensions were longer than duration of $\beta$-SRDs during antisaccades $(p<0.001$, Tukey-Kramer test; Fig. 5B). The effect of the positions of contact pairs were not significant, but the interaction between tasks and positions of contact pairs was significant $(p=0.032$, two-way ANOVA; Fig. $5 B$ ). During wrist extension, durations of $\beta$-ERDs in the middle contact pairs were longer than those in the ventral contact pairs $(p=0.032$, Tukey-Kramer test). During prosaccades, durations of $\beta$-SRDs in the ventral contact

B Antisaccade

C Wrist extension

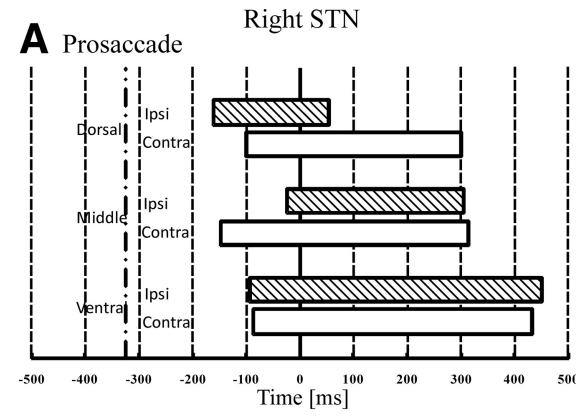

Left STN
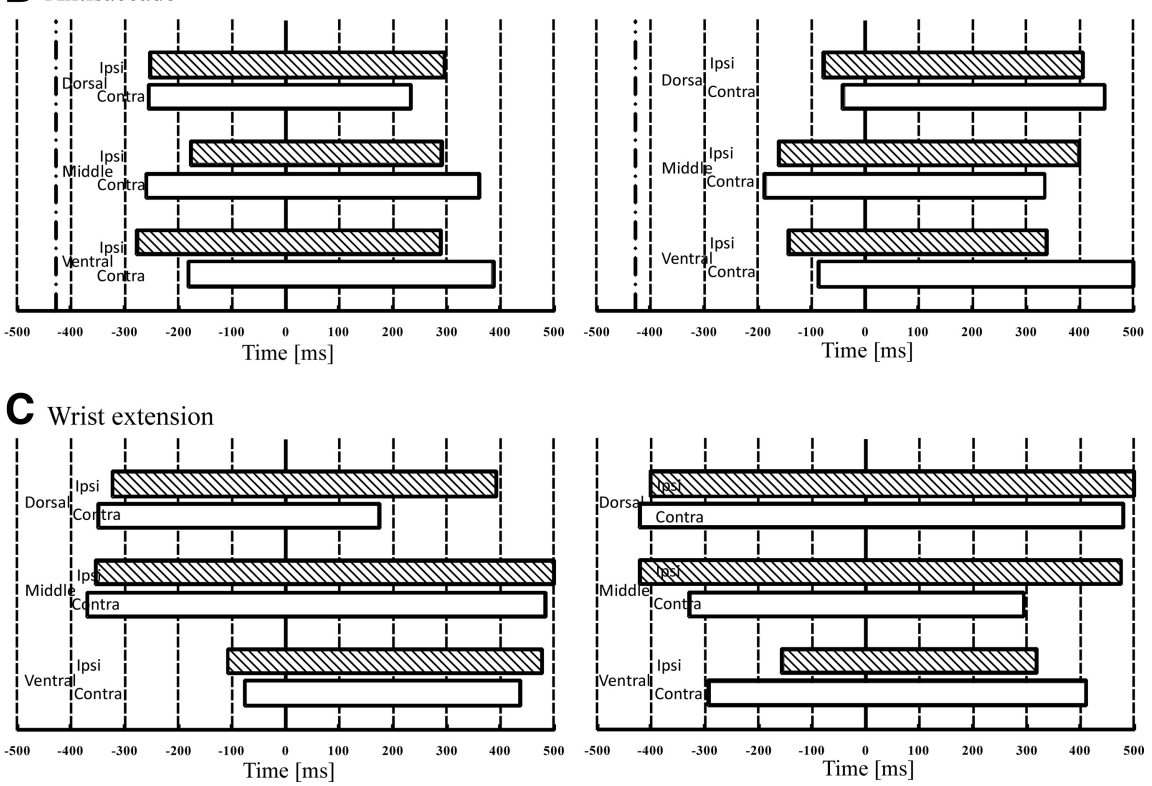

Figure 4. Ranges of $\beta$-SRDs and $\beta$-ERDs. Averaged ranges of $\beta$-SRDs recorded from each pair of DBS contacts in each tasks. Time 0 represents saccade or movement onset. The dash-dot lines represents the averaged visual cue onset time. Hatched bars represent the ranges of $\beta$-SRDs in the STN ipsilateral to saccade direction. White bars represent the ranges of $\beta$-SRDs in the STN contralateral to saccade direction.

pairs showed a trend of being longer than those in the middle contact pairs ( $p=0.088$, Tukey-Kramer test), but were not significant. Durations of $\beta$-SRDs during antisaccades were not significantly different among the positions of contact pairs. 

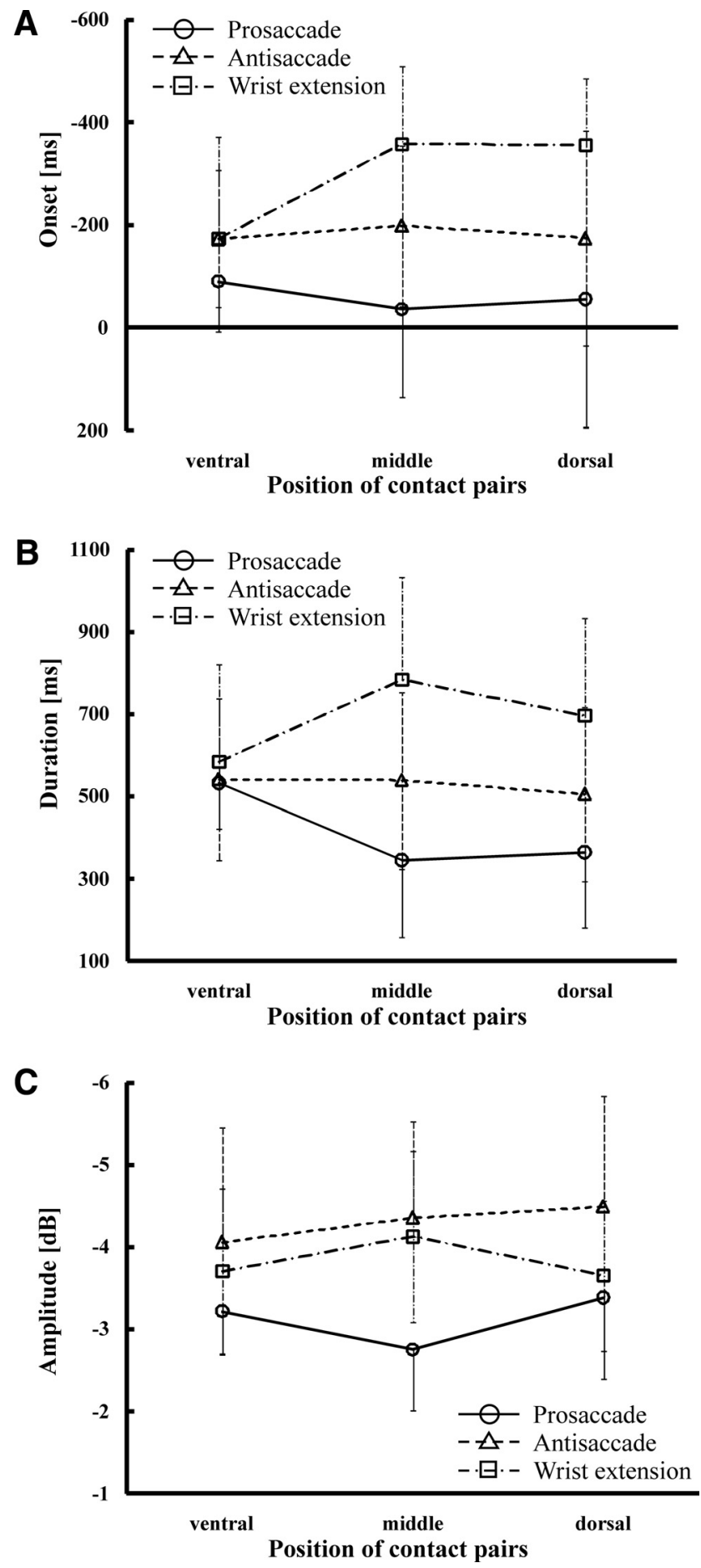

Figure 5. Averaged onset, duration, and amplitude of $\beta$-SRDs and $\beta$-ERDs. A, Average onset of $\beta$-SRDs during prosaccades and antisaccades and $\beta$-ERDs during self-paced wrist extension. Time 0 is the saccade or movement onset time. $\boldsymbol{B}, \boldsymbol{C}$, Duration and amplitude of $\beta$-SRDs and $\beta$-ERDs. Error bars represent SD.

The amplitudes of $\beta$-SRDs and $\beta$-ERDs showed normal distributions ( $p>0.1$, Kolmogorov-Smirnov test) and were different among the tasks ( $p<0.001$, two-way ANOVA), although these did not differ among the positions of contact pairs (Fig. $5 C$ ). The interaction between the tasks and the positions of contact pairs was not significant (Fig. 5C). Amplitudes of $\beta$-SRDs for antisaccades were larger than those of $\beta$-ERDs for wrist extension ( $p=0.049$, Tukey-Kramer test), and amplitudes of $\beta$-ERDs for wrist extension were larger than those of $\beta$-SRDs for prosaccades ( $p=0.008$, Tukey-Kramer test).

The onsets, durations, and amplitudes of $\beta$-SRDs were not correlated with Hoehn and Yahr stages, UPDRS-III scores, age at surgery, onset age of disease, or disease duration. The durations of $\beta$-ERDs with wrist movements correlated with Hoehn and Yahr stages $(r=0.639, p=0.004)$ and UPDRS-III scores during both the off-medication $(r=0.531, p<0.001)$ and on-medication states $(r=0.745, p=0.023)$. The onsets, durations, and amplitudes of $\beta$-ERDs for wrist movements were not correlated with age at surgery, onset age of disease, or disease duration. The onset latencies of prosaccades were correlated with the durations $(r=0.615, p=0.025)$ but not the onsets of $\beta$-SRDs $(r=0.076, p=0.805)$. The onset latencies of antisaccades showed a nonsignificant trend for correlation with the $\beta$-SRD onsets $(r=-0.424, p=0.071)$, but not the durations of $\beta$-SRDs $(r=-0.293, p=0.223)$.

The onsets of $\beta$-SRDs in the right STN were earlier than those in the left STN during both prosaccade and antisaccade ( $p=$ 0.001 , two-way ANOVA), although durations and amplitudes of $\beta$-SRDs did not differ significantly between the right and left STN (Fig. 6). The onset, duration, and amplitudes of $\beta$-SRDs did not differ between the ipsilateral and contralateral STN (Fig. 6). The onsets of $\beta$-SRDs were earlier in the on-medication state than in the off-medication state during both prosaccades and antisaccades ( $p=0.016$, two-way ANOVA). The durations and amplitudes of $\beta$-SRDs did not differ significantly with medication status (Fig. 6).

The locations of DBS contacts demonstrated by postoperative MRI are shown in Figure 7 . Contact pairs in which $\beta$-SRDs were observed with prosaccades appeared to be more dorsal than those with antisaccades or with wrist movements, but the differences were not significant ( $p=0.159$, KruskalWallis rank-sum test).

\section{Discussion}

The observation of $\beta$-SRDs in the STN in PD patients extends previous studies showing changes in neuronal firing of single units in the STN with eye movements (Fawcett et al., 2005) and saccade-related premovement potentials (Fawcett et al., 2007). Beta-band desynchronization in the STN is thought to be involved in the preparation (Kühn et al., 2004) and execution of limb movements (Cassidy et al., 2002). Our findings suggest that beta-band desynchronization in the STN plays a role also in the preparation and execution of saccades. Indeed, we observed a trend in the correlation between the onsets and durations of $\beta$-SRDs in the STN and saccade onsets.

We observed that $\beta$-SRDs started earlier, were sustained for longer, and had larger amplitudes for antisaccades than for prosaccades, suggesting that $\beta$-SRDs in the STN are involved not only in execution of movements, but also in the inhibition of unwanted movements. This finding in the STN is in agreement with the greater modulations of neuronal activities in the globus pallidus (pars externa and pars interna) in monkeys with antisaccades compared with prosaccades, the areas that have direct input and output connections with the STN (Yoshida and Tanaka, 2009).

\section{Bilateral $\boldsymbol{\beta}$-desynchronization for saccades}

We observed $\beta$-SRDs in either the ipsilateral or the contralateral STN and bilaterally in different subjects for both the prosaccade and the antisaccade tasks, suggesting that the STN is involved in saccades to both the ipsilateral and contralateral space. Although variations in contact locations from patient to patient may account for some of 
these results, both ipsilateral and contralateral circuits are likely recruited to prepare for an upcoming saccade. We predicted that $\beta$-SRDs in the contralateral STN might start earlier and be sustained for longer than those in the ipsilateral STN, because both fixation and saccades are controlled predominantly by the neural connections from the superior colliculus contralateral to the saccade direction (Takahashi et al., 2005). However, we did not find any difference in the onset, duration, or amplitude of $\beta$-SRDs in the contralateral and the ipsilateral STN. The model suggested by Isoda and Hikosaka (2008) may explain these findings by suggesting that STN neurons are activated for saccades in both directions in GO and NOGO tasks. Another hypothesis is that both limb and eye movements involve bilateral neural circuits. Previous studies demonstrated bilateral movement-related potentials and $\beta$-ERDs in the cortices (Stancák and Pfurtscheller, 1996) and in the STN (Paradiso et al., 2003; Kühn et al., 2004; Alegre et al., 2005) with unilateral hand movements, which is consistent with our observation of bilateral $\beta$-SRDs and bilateral $\beta$-ERDs for wrist movements in the STN.

\section{Differences of $\boldsymbol{\beta}$-desynchronizations among the tasks}

$\beta$-SRDs for antisaccades were observed in 19 of 20 patients, whereas $\beta$-SRDs for prosaccades were observed in 13 of 20 patients, suggesting that the generation of antisaccades likely involves more neurons or neurons in different locations than prosaccades for both fixation and saccades in the STN. This is consistent with the observation of neurons involved in both fixation and saccades in the monkey STN (Matsumura et al., 1992). More than three quarters of the contact pairs with $\beta$-SRDs for prosaccades overlapped with those for antisaccades ( 21 of 27 contact pairs, or $77.8 \%$ ), whereas the contact pairs with $\beta$-SRDs for antisaccades overlapped less with those for prosaccades ( 21 of 53 contact pairs, or $39.6 \%$ ). This suggests that greater areas on the STN related to saccades and fixation are involved in antisaccades than prosaccades. Only 4 of $27(14.8 \%)$ contact pairs showed $\beta$-SRDs for both ipsilateral and contralateral prosaccades, whereas 20 of $53(37.7 \%)$ contact pairs showed $\beta$-SRDs for both directions during antisaccades. Selectivity of saccade direction was observed in the saccade-related neurons in the monkey STN (Matsumura et al., 1992), so distribution of neuronal activity changes for prosaccades or antisaccades may be different for saccades toward the ipsilateral and contralateral directions.

$\beta$-ERDs for wrist movements started earlier and were sustained for longer than $\beta$-SRDs, whereas the amplitudes of $\beta$-ERDs for wrist movements were larger than $\beta$-SRDs for prosaccades but smaller than $\beta$-SRDs for antisaccades. Self-paced wrist extensions were executed without external cues, whereas the prosaccade and antisaccade tasks were executed with visual cues. Therefore, the different results may be because of a difference between internal- and external-cued movements, or may be due to longer duration of muscle activities or greater muscle involvement in wrist extension than simple horizontal saccades.
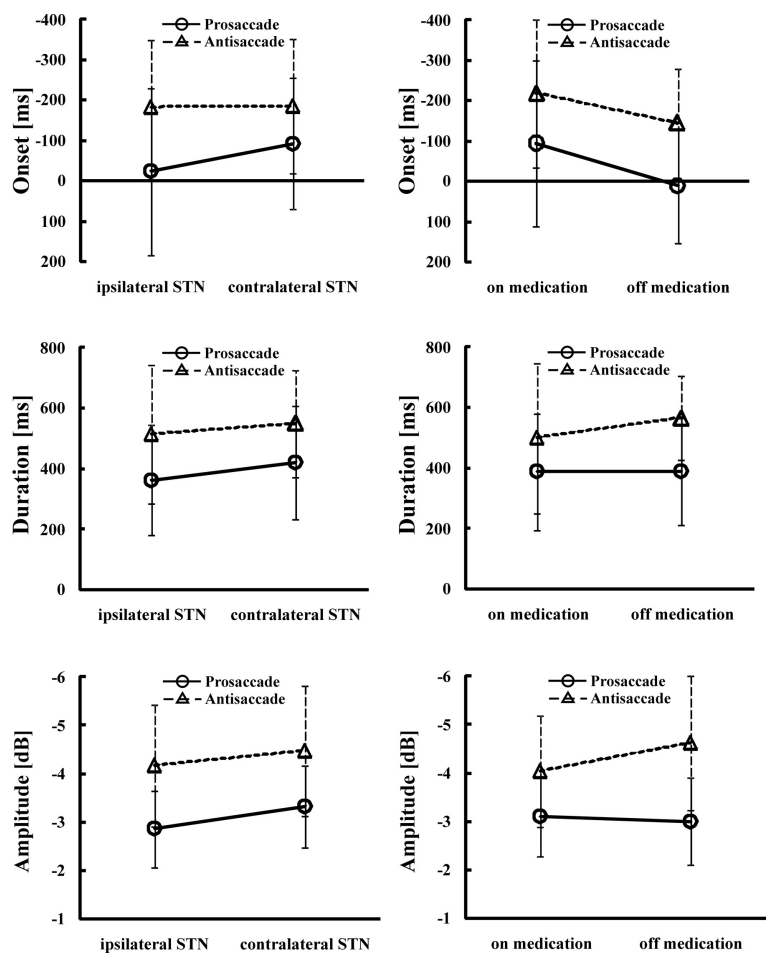

Figure 6. Effects of STN laterality and medication on $\beta$-SRDs and $\beta$-ERDs. Upper row shows average onset of $\beta$-SRDs during ween the right and the left STN. Middle and right columns show comparison between ipsilateral and contralateral STN to saccade direction and between on-medication and off-medication patients.

\section{Localization of $\beta$-SRDs in the STN}

In nonhuman primates, the ventral STN receives neural inputs from the frontal eye field and the supplementary eye field (Monakow et al., 1978; Huerta et al., 1986; Huerta and Kaas, 1990), whereas signals for limb movements project from the primary and supplementary motor cortices to the dorsal STN (Monakow et al., 1978, Nambu et al., 1996). We observed that $\beta$-ERDs for wrist movements in the middle contact pairs, which generally represent the dorsal part of the STN (Fig. 7), were sustained for longer than those in the other contact pairs, which represent ventral STN or were outside the STN. The onsets, durations, and amplitudes of $\beta$-SRDs for saccades did not differ significantly with the positions of contact pairs. It is consistent with sparse distribution of eye movement-related cells in the dorsal STN and greater concentration in the middle and the ventral STN of PD patients (Fawcett et al., 2005). This discrepancy between our results and animal studies may be because the recording sites were limited in human DBS electrodes compared with animal studies, because the DBS electrode was larger than the microelectrodes used in animal studies, or because the LFPs we recorded represent populations of neurons whereas the single unit recordings used in animal studies represent activity of each neuron. The different distributions of beta activities in the STN between normal monkeys and PD patients reported here may also be related to the parkinsonian state. $\beta$-SRDs and $\beta$-ERDs for wrist movements were observed also in the dorsal contact pairs that are sometimes outside of the STN, possibly in the zona incerta (ZI). $\beta$-SRDs have been recorded from saccade-related neurons in the ZI (Hikosaka and Wurtz, 1983), and $\beta$-ERDs for wrist movements have been recorded from the ZI neurons projecting to the motor thalamus (Barthó et al., 2002). 
A Prosaccade

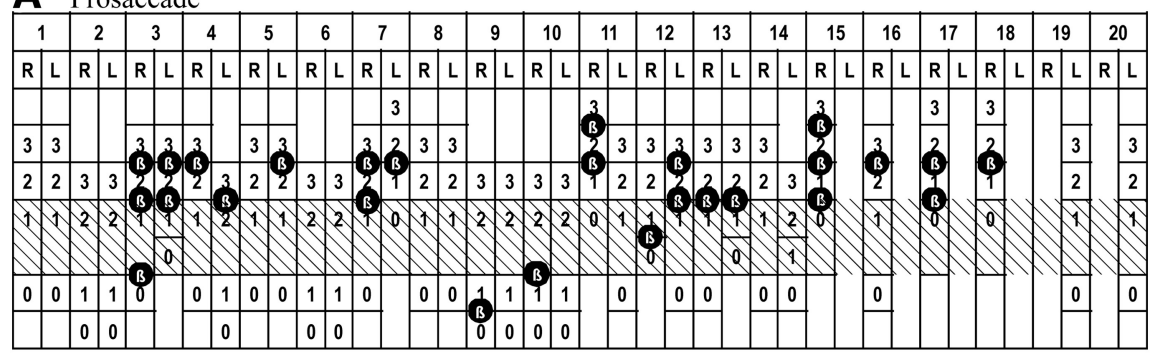

B Antisaccade

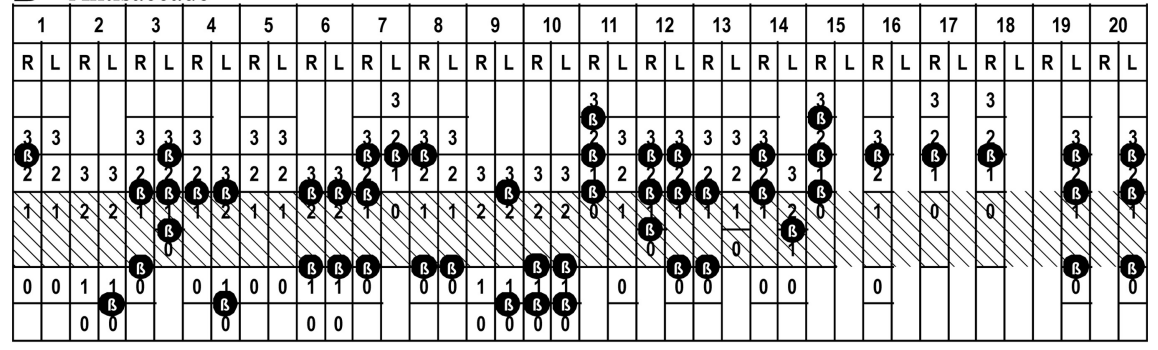

C Self-paced wrist extension

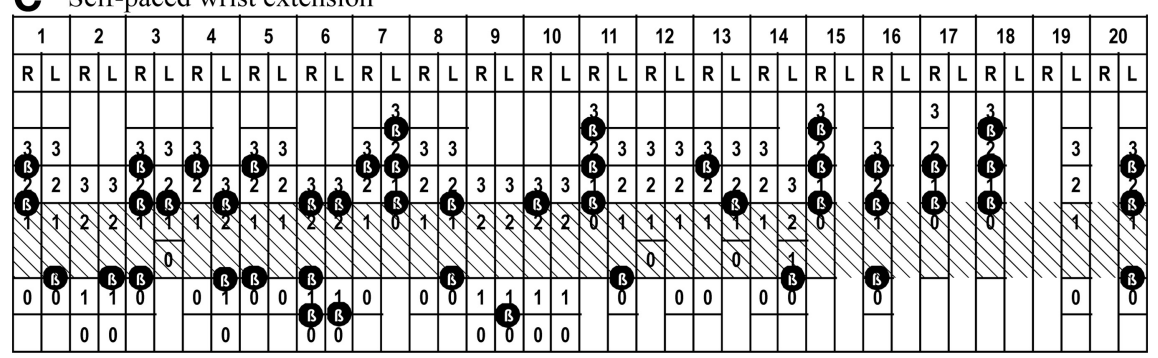

Figure 7. Location of DBS contacts and $\beta$-SRDs. Hatched area represents the STN. Black circles with the character $\beta$ represent locations where the $\beta$-SRDs or $\beta$-ERDs were observed. R and L represent the right and the left STN. Each patient is represented by a number.

\section{$\boldsymbol{\beta}$-desynchronizations and laterality, medication, and symptoms}

$\beta$-SRDs started earlier in the right STN than in the left STN in our study. This may be due to the fact that visually guided saccades require spatial attention that is known to be dominant in the right hemisphere (Khonsari et al., 2007; Petit et al., 2009). $\beta$-SRDs also started earlier in patients on antiparkinsonian medication than in those off medication, although we could not rule out a selection bias because there were different patients in the two groups. Previous studies showed that levodopa reduced the baseline betaband oscillation in the STN in PD patients (Levy et al., 2002). Therefore, earlier onset of $\beta$-SRDs with medication may be because beta-band power reduction reaches the threshold earlier due to the reduced baseline beta-band oscillations.

We found correlations only between the durations of $\beta$-ERDs for wrist movements and UPDRS motor score and Hoehn and Yahr stage. This may be related to the longer time required for movement initiation or slower movements in more advanced PD patients. Because these motor scores represent only somatomotor impairment, it is not surprising that $\beta$-SRDs were not correlated with these motor scores. Baseline beta-band oscillations did not appear to be correlated with motor impairment in offmedication PD patients (Giannicola et al., 2010), which may explain why the amplitudes of $\beta$-ERDs for wrist movements showed no correlation with parkinsonian motor signs.

\section{Limitations of this study}

There are several limitations to this study. First, we recorded LFPs $1-5 \mathrm{~d}$ after DBS surgery, when the STN and other brain areas may be affected by the electrode insertion and edema in the vicinity of the recordings. However, a recent study showed that the peak frequencies and power of the $\beta$-band remained stable between 2 and $30 \mathrm{~d}$ after DBS electrode implantation (Rosa et al., 2010, 2011). Second, some patients were drowsy during the experiments, which may have reduced their task performance. Third, it was not possible to record from normal controls. Fourth, we did not randomize patients to on- and off-medication groups, so we could not conclude that the on/off comparisons were free from a selection bias.

\section{Conclusion}

Saccade-related beta-band desynchronization in the STN is more involved in eye movements that involve greater volitional control, such as antisaccades compared with prosaccades. Furthermore, $\beta$-SRDs were found bilaterally, suggesting both the ipsilateral and contralateral STN is involved in saccade generation. $\beta$-SRDs in the STN started earlier, were sustained for longer, and had a larger amplitude during antisaccades than during prosaccades, suggesting that $\beta$-SRDs may be involved in both inhibition of reflexive responses and volitional execution of saccades. Moreover, the changes seen for both limb and eye movements suggest that oscillatory activities in the $\mathrm{BG}$ are related to both the BG-thalamocortical loops and to BG-brainstem projections such as the BG-substantia nigra pars reticulata-superior colliculus circuit involved in the control of saccades.

\section{References}

Alegre M, Alonso-Frech F, Rodríguez-Oroz MC, Guridi J, Zamarbide I, Valencia M, Manrique M, Obeso JA, Artieda J (2005) Movement-related changes in oscillatory activity in the human subthalamic nucleus: ipsilateral vs. contralateral movements. Eur J Neurosci 22:2315-2324. CrossRef Medline

Baker SN, Olivier E, Lemon RN (1997) Coherent oscillations in monkey motor cortex and hand muscle EMG show task-dependent modulation. J Physiol 501:225-241. CrossRef Medline

Barthó P, Freund TF, Acsády L (2002) Selective GABAergic innervation of thalamic nuclei from zona incerta. Eur J Neurosci 16:999-1014. CrossRef Medline

Braun D, Breitmeyer BG (1988) Relationship between directed visual attention and saccadic reaction times. Exp Brain Res 73:546-552. CrossRef Medline

Briand KA, Strallow D, Hening W, Poizner H, Sereno AB (1999) Control of voluntary and reflexive saccades in Parkinson's disease. Exp Brain Res 129:38-48. CrossRef Medline

Cassidy M, Mazzone P, Oliviero A, Insola A, Tonali P, Di Lazzaro V, Brown P (2002) Movement-related changes in synchronization in the human basal ganglia. Brain 125:1235-1246. CrossRef Medline

Chan F, Armstrong IT, Pari G, Riopelle RJ, Munoz DP (2005) Deficits in saccadic eye-movement control in Parkinson's disease. Neuropsychologia 43:784-796. CrossRef Medline

Delinte A, Gomez CM, Decostre MF, Crommelinck M, Roucoux A (2002) 
Amplitude transition function of human express saccades. Neurosci Res 42:21-34. CrossRef Medline

Donoghue JP, Sanes JN, Hatsopoulos NG, Gaál G (1998) Neural discharge and local field potential oscillations in primate motor cortex during voluntary movements. J Neurophysiol 79:159-173. Medline

Fawcett AP, Dostrovsky JO, Lozano AM, Hutchison WD (2005) Eye movement-related responses of neurons in human subthalamic nucleus. Exp Brain Res 162:357-365. CrossRef Medline

Fawcett AP, Cunic D, Hamani C, Hodaie M, Lozano AM, Chen R, Hutchison WD (2007) Saccade-related potentials recorded from human subthalamic nucleus. Clin Neurophysiol 118:155-163. CrossRef Medline

Fawcett AP, González EG, Moro E, Steinbach MJ, Lozano AM, Hutchison WD (2010) Subthalamic Nucleus Deep Brain Stimulation Improves Saccades in Parkinson's Disease. Neuromodulation 13:17-25. CrossRef Medline

Fischer B, Weber H (1992) Characteristics of "anti" saccades in man. Exp Brain Res 89:415-424. Medline

Giannicola G, Marceglia S, Rossi L, Mrakic-Sposta S, Rampini P, Tamma F, Cogiamanian F, Barbieri S, Priori A (2010) The effects of levodopa and ongoing deep brain stimulation on subthalamic beta oscillations in Parkinson's disease. Exp Neurol 226:120-127. CrossRef Medline

Hamani C, Moro E, Zadikoff C, Poon YY, Lozano AM (2008) Location of active contacts in patients with primary dystonia treated with globus pallidus deep brain stimulation. Neurosurgery 62:217-223; discussion 223225. CrossRef Medline

Hikosaka O, Wurtz RH (1983) Visual and oculomotor functions of monkey substantia nigra pars reticulata. I. Relation of visual and auditory responses to saccades. J Neurophysiol 49:1230-1253. Medline

Hikosaka O, Takikawa Y, Kawagoe R (2000) Role of the basal ganglia in the control of purposive saccadic eye movements. Physiol Rev 80:953-978. Medline

Huerta MF, Kaas JH (1990) Supplementary eye field as defined by intracortical microstimulation: connections in macaques. J Comp Neurol 293: 299-330. CrossRef Medline

Huerta MF, Krubitzer LA, Kaas JH (1986) Frontal eye field as defined by intracortical microstimulation in squirrel monkeys, owl monkeys, and macaque monkeys: I. Subcortical connections. J Comp Neurol 253:415-439. CrossRef Medline

Isoda M, Hikosaka O (2008) Role for subthalamic nucleus neurons in switching from automatic to controlled eye movement. J Neurosci 28: 7209-7218. CrossRef Medline

Kalesnykas RP, Hallett PE (1987) The differentiation of visually guided and anticipatory saccades in gap and overlap paradigms. Exp Brain Res 68: 115-121. Medline

Khonsari RH, Lobel E, Milea D, Lehéricy S, Pierrot-Deseilligny C, Berthoz A (2007) Lateralized parietal activity during decision and preparation of saccades. Neuroreport 18:1797-1800. CrossRef Medline

Kühn AA, Williams D, Kupsch A, Limousin P, Hariz M, Schneider GH, Yarrow K, Brown P (2004) Event-related beta desynchronization in human subthalamic nucleus correlates with motor performance. Brain 127: 735-746. CrossRef Medline

Kuriakose R, Saha U, Castillo G, Udupa K, Ni Z, Gunraj C, Mazzella F, Hamani C, Lang AE, Moro E, Lozano AM, Hodaie M, Chen R (2010) The nature and time course of cortical activation following subthalamic stimulation in Parkinson's disease. Cereb Cortex 20:1926-1936. CrossRef Medline

Levy R, Hutchison WD, Lozano AM, Dostrovsky JO (2000) High-frequency synchronization of neuronal activity in the subthalamic nucleus of parkinsonian patients with limb tremor. J Neurosci 20:7766-7775. Medline

Levy R, Ashby P, Hutchison WD, Lang AE, Lozano AM, Dostrovsky JO (2002) Dependence of subthalamic nucleus oscillations on movement and dopamine in Parkinson's disease. Brain 125:1196-1209. CrossRef Medline

Matsumura M, Kojima J, Gardiner TW, Hikosaka O (1992) Visual and oculomotor functions of monkey subthalamic nucleus. J Neurophysiol 67: 1615-1632. Medline
Monakow KH, Akert K, Künzle H (1978) Projections of the precentral motor cortex and other cortical areas of the frontal lobe to the subthalamic nucleus in the monkey. Exp Brain Res 33:395-403. Medline

Murthy VN, Fetz EE (1992) Coherent 25- to 35-Hz oscillations in the sensorimotor cortex of awake behaving monkeys. Proc Natl Acad Sci U S A 89:5670-5674. CrossRef Medline

Nambu A, Takada M, Inase M, Tokuno H (1996) Dual somatotopical representations in the primate subthalamic nucleus: evidence for ordered but reversed body-map transformations from the primary motor cortex and the supplementary motor area. J Neurosci 16:2671-2683. Medline

Paradiso G, Saint-Cyr JA, Lozano AM, Lang AE, Chen R (2003) Involvement of the human subthalamic nucleus in movement preparation. Neurology 61:1538-1545. CrossRef Medline

Petit L, Zago L, Vigneau M, Andersson F, Crivello F, Mazoyer B, Mellet E, Tzourio-Mazoyer N (200) Functional asymmetries revealed in visually guided saccades: an fMRI study. J Neurophysiol 9;102:2994-3003.

Reuter-Lorenz PA, Oonk HM, Barnes LL, Hughes HC (1995) Effects of warning signals and fixation point offsets on the latencies of pro- versus antisaccades: implications for an interpretation of the gap effect. Exp Brain Res 103:287-293. Medline

Rivaud-Péchoux S, Vermersch AI, Gaymard B, Ploner CJ, Bejjani BP, Damier P, Demeret S, Agid Y, Pierrot-Deseilligny C (2000) Improvement of memory guided saccades in parkinsonian patients by high frequency subthalamic nucleus stimulation. J Neurol Neurosurg Psychiatry 68:381-384. CrossRef Medline

Rosa M, Marceglia S, Servello D, Foffani G, Rossi L, Sassi M, Mrakic-Sposta S, Zangaglia R, Pacchetti C, Porta M, Priori A (2010) Time dependent subthalamic local field potential changes after DBS surgery in Parkinson's disease. Exp Neurol 222:184-190. CrossRef Medline

Rosa M, Giannicola G, Servello D, Marceglia S, Pacchetti C, Porta M, Sassi M, Scelzo E, Barbieri S, Priori A (2011) Subthalamic local field beta oscillations during ongoing deep brain stimulation in Parkinson's disease in hyperacute and chronic phases. Neurosignals 19:151-162. CrossRef Medline

Sanes JN, Donoghue JP (1993) Oscillations in local field potentials of the primate motor cortex during voluntary movement. Proc Natl Acad Sci U S A 90:4470-4474. CrossRef Medline

Stancák A Jr, Pfurtscheller G (1996) Event-related desynchronisation of central beta-rhythms during brisk and slow self-paced finger movements of dominant and nondominant hand. Cogn Brain Res 4:171-183. CrossRef

Takahashi M, Sugiuchi Y, Izawa Y, Shinoda Y (2005) Synaptic inputs and their pathways from fixation and saccade zones of the superior colliculus to inhibitory burst neurons and pause neurons. Ann N Y Acad Sci 1039: 209-219. CrossRef Medline

Tomlinson CL, Stowe R, Patel S, Rick C, Gray R, Clarke CE (2010) Systematic review of levodopa dose equivalency reporting in Parkinson's disease. Mov Disord 25:2649-2653. CrossRef Medline

Weber H, Latanov A, Fischer B (1993) Context dependent amplitude modulations of express and regular saccades in man and monkey. Exp Brain Res 93:335-344. Medline

White OB, Saint-Cyr JA, Tomlinson RD, Sharpe JA (1983) Ocular motor deficits in Parkinson's disease. II. Control of the saccadic and smooth pursuit systems. Brain 106:571-587. CrossRef Medline

Williams D, Kühn A, Kupsch A, Tijssen M, van Bruggen G, Speelman H, Hotton G, Loukas C, Brown P (2005) The relationship between oscillatory activity and motor reaction time in the parkinsonian subthalamic nucleus. Eur J Neurosci 21:249-258. CrossRef Medline

Yoshida A, Tanaka M (2009) Enhanced modulation of neuronal activity during antisaccades in the primate globus pallidus. Cereb Cortex 19: 206-217. CrossRef Medline

Yugeta A, Terao Y, Fukuda H, Hikosaka O, Yokochi F, Okiyama R, Taniguchi M, Takahashi H, Hamada I, Hanajima R, Ugawa Y (2010) Effects of STN stimulation on the initiation and inhibition of saccade in Parkinson disease. Neurology 74:743-748. CrossRef Medline 